\title{
The Cayman Turtle Farm: Why We Can't Have Our Green Turtle and Eat it Too
}

\author{
Neil D'Cruze • Rachel Alcock • Marydele Donnelly
}

Accepted: 5 September 2014/Published online: 9 October 2014

(C) The Author(s) 2014. This article is published with open access at Springerlink.com

\begin{abstract}
The Cayman Turtle Farm (CTF) is the only facility in the world that commercially produces green sea turtles (Chelonia mydas) for human consumption. The CTF has operated at a significant financial loss for much of its 45 years history and is maintained by substantial Cayman Island Government subsidies. These subsidies run into millions of Caymanian dollars and dwarf the funding allocated to The Caymanian Department of Environment to protect its unique biodiversity each year. We argue that it is time for the CTF to terminate its sea turtle 'farming' initiative. Supporters argue that the CTF helps to conserve green turtles by providing legal and sustainable turtle meat for local Caymanian consumption. Opponents maintain that farmed turtle meat cannot serve as an effective economically viable substitute, and that the facility potentially harms Caribbean green turtle populations by promoting turtle meat consumption, when other Caribbean nations increasingly prohibit this practice. The CTF's records demonstrate that commercial production has come at the expense of tens of thousands of sea turtles. We question the ethics of sea turtle farming and argue that the CTF could better contribute to conservation if it transitioned into a rehabilitation, research and education facility (similar to the former sea turtle ranch Ferme Corail, now known as the Kélonia: Observatory of Marine Turtles). Recommended first steps include prohibiting the sale of sea turtle products to international tourists, engaging with stakeholders, and assessing the true scale of local consumer demand for green turtle meat.
\end{abstract}

N. D’Cruze $(\bowtie) \cdot R$. Alcock

World Animal Protection (formally the World Society for the Protection of Animals),

5th Floor, 222 Gray's Inn Road, London WC1X 8HB, UK

e-mail: NeilDCruze@worldanimalprotection.org

M. Donnelly

Sea Turtle Conservancy, 3775 Bonnybridge Place, Ellicott City, MD 21043, USA

e-mail: marydele@conserveturtles.org 
Keywords Cayman Islands · Cayman Turtle Farm · Chelonia mydas · Commercial utilisation · Green sea turtle $\cdot$ Kélonia $\cdot$ Sea turtle farming

\section{Introduction}

For centuries humans have hunted sea turtles for meat and other products (Frazier 2003). Unsustainable exploitation has had a detrimental impact on many wild sea turtle populations and is a major contributing factor in global declines (Lutcavage et al. 1997). Most nations now prohibit consumption although some societies still tolerate direct take for subsistence (Pritchard 2011). Green turtles are a significant cultural feature in the Cayman Islands (Aiken et al. 2001); turtle stew is the national dish, and local demand for turtle meat continues (Bell et al. 2005, 2007). Today the Cayman Islands are the only nation that commercially produces green turtles to satisfy its domestic market (WSPA 2012).

The Cayman Turtle Farm (CTF) was established as Mariculture Ltd in 1968 to commercially raise green turtles (Fosdick and Fosdick 1994). The founding stock of 477,000 eggs and 148 adults and sub-adults were collected between 1968 and 1978 from Ascension Island, Costa Rica, Guyana, Mexico and Suriname and Nicaraguan waters (Cayman Turtle Farm 2002). By 1975 the CTF demonstrated that it could rear green turtles to maturity from eggs produced on site, negating the need to obtain eggs from the wild from 1978 onwards (Ross 1999).

In recognition of their endangered plight, in 1975 the Convention on International Trade in Endangered Species (CITES) prohibited international trade in Atlantic green turtles and the majority of the world's other sea turtle populations by including them in Appendix I (Donnelly 1994). The CITES Parties also adopted captive breeding requirements with strict controls to allow trade in these species from 'farms' (CITES Conf. Res. 2.12). To ensure they were closed cycle systems CITES only permitted 'farms' to engage in the commercial sale of second generation offspring. Although this requirement should have excluded the CTF, the farm proposed to re-open international sea turtle trade with first generation turtles that had been produced by its founding or parent generation. However, debate surrounded the $\mathrm{CTF}$ with regards to whether it had achieved requisite legal captive breeding status (Donnelly 1994).

Sea turtle farming opponents expressed concern that the increased availability of legal farmed turtle meat would stimulate demand, which the CTF could not satisfy, and therefore increase pressure on wild populations through poaching (Ehrenfeld 1982). With high production costs and a potential preference for wild meat amongst Caymanians, it was also feared farmed meat might not represent an economically viable substitute (Dodd 1982). Additionally, opponents criticised the CTF for technical reasons (Donnelly 1994).

Subsequently, in 1983 and 1985 the CITES Parties rejected proposals from the CTF to market green turtle products internationally. As the Cayman Islands are a UK dependency, domestic trade with the UK technically remained legal, but the CTF's inability to export green turtle meat via the United States of America as a result of the 
U.S. Endangered Species Act, made farming economically unfeasible (Ross 1999). In 2002 the CTF made another attempt to trade internationally by proposing that it be allowed to register as a CITES captive breeding facility in order to supply green turtle shells to international markets (Cayman Turtle Farm 2002); this proposal was rejected (Donnelly 2011).

For much of its history, the CTF has been supported financially by the Cayman Islands Government. Public marketing has helped create the perception that the CTF's commercial operation is necessary to ensure the continued survival of local wild green turtles (e.g., Cayman Compass 2010). Our primary purpose herein is to demonstrate why this notion should be rejected. We also provide background information to aid discussions focussed on why and how the CTF could successfully transition away from commercial turtle production into a regional rehabilitation, release and education centre for Caribbean sea turtles.

Although controversy continues to surround the CTF for reasons related to human health, animal welfare, and its conservation activities (Warwick et al. 2012; Arena et al. 2014), our current focus is on the economic feasibility of commercial green turtle production at the CTF.

\section{Is Sea Turtle Farming in the Cayman Islands Economically Feasible?}

Following a thorough review, we conclude that the CTF's own records together with other data demonstrate that it represents an economically unfeasible model. Due to high production costs, associated husbandry problems and CITES restrictions on international trade, the CTF has encountered serious economic difficulties throughout its existence (Duguay 2009).

The CTF officially declared bankruptcy in 1975 and was purchased by German investors; it went into receivership in 1983 and was then purchased by its present owner, the Cayman Islands Government (Fosdick and Fosdick 1994). Today, the CTF survives thanks to large annual Government subsidies and income from visitors (WSPA 2012). Between 2007 and 2011 it received over 44 million Caymanian dollars in subsidies (on average almost 9 million Caymanian dollars a year) (Cayman Turtle Farm 2012a). Supporters blame the CTF's current economic woes on damage from Hurricane Michelle in 2001, and the subsequent decision to increase revenue through the costly 'Boatswains Beach' redevelopment which began in 2005 and was aimed at making the facility more appealing to tourists (Morriss 2006). Historically, however, the CTF has never been economically stable for more than a couple of years at a time (Fosdick and Fosdick 1994).

Farmed sea turtle meat comes with significant costs in terms of captive morbidity and mortality (Ross 1999). Currently the CTF has 9,860 green turtles (Cayman Turtle Farm 2013a). However, after decades of operation, it is still failing to overcome fundamental technical problems, including production, husbandry, and mortality (Balazs et al. 2013). Internal in-depth assessments (Godley 2002; Cayman Turtle Farm 2012b) and a follow-up 'independent assessment' (Balazs et al. 2013) document the extent to which production is hampered by low hatchling survival rates and high levels of morbidity and mortality. Between 2007 and 2011, 2,299 
turtle deaths were documented (Cayman Turtle Farm 2012c) and only $6.2 \%$ of eggs laid during this period produced offspring that survived 12 months or more (Cayman Turtle Farm 2012c).

Technically, much has been learned about the biology and husbandry of green turtles in captivity at the $\mathrm{CTF}$, including methods to produce second generation offspring (Wood and Wood 1990). Nevertheless, documented disease, stress, injuries and cannibalism caused by the intensive commercial conditions have continually dogged the CTF, and are likely responsible for on-going reported health and mortality problems (Godley 2002). In addition in July 2012, 299 green sea turtles died when they were accidentally left overnight without water (Wildlife Extra 2012) (Fig. 1), an event which drew significant domestic and international attention to the facility (Cayman News Service 2012). This event exemplified how the CTF has struggled to meet even the most basic animal welfare standards associated with commercial production.

The CTF has, in some cases, tried to address the concerns raised by increasing veterinary supervision and testing interventions to reduce morbidity and mortality rates (Balazs et al. 2013). But such interventions might simply represent a 'quick fix' for dealing with the symptoms of the problem (i.e., the health of the animals) rather than addressing the root causes of unsuitable captive conditions (i.e., their welfare). Yet even with the introduction of these measures, and after the various commissioned assessments, turtles continue to remain in shallow barren concrete tanks with poor water quality (Fig. 2).

The added expense of any intervention measures to improve the health of the turtles at the CTF may also raise production costs to a point in which application becomes economically unfeasible and unrealistic (WSPA 2012). Because when key aspects of green turtle biology and behaviour (e.g., their dietary requirements, and their solitary and migratory nature) are taken into account, it is difficult to foresee how required husbandry standards can ever be met under intensive farming conditions (Ross 1999).

The capital-intensive costs of commercial green turtle production means that the CTF has been forced to sell its meat at a higher than desired price (Cayman Compass 2010). The high price of wildlife products can lead to reduced competitiveness (Ross 1999; Dutton et al. 2011) and may result in increased poaching (Cayman Compass 2010; WSPA 2012). To address this concern the CTF announced plans to drop meat prices by as much as $25 \%$ in August 2013 (Cayman Compass 2013a). However, as this action has required an increase in green turtle meat production (and an associated increase in the number of animals at the CTF) there are fears that this will only serve to further exacerbate the animal welfare concerns, including the morbidity and mortality issues highlighted above (Cayman Compass 2013b).

It has also been reported that green turtle production at the CTF is falling. During Hurricane Michelle, $75 \%$ of the breeding stock was lost (Cayman Turtle Farm 2013c) and older breeders, some of which have been in captivity for more than 40 years, are expected to be near the end of their reproductive lives, and as a result are no longer housed in the 'breeding pool'. Some records are missing, but those available show that the CTF has experienced poor production throughout its history with farm-reared breeders being the least productive (Cayman Turtle Farm 2013b). 


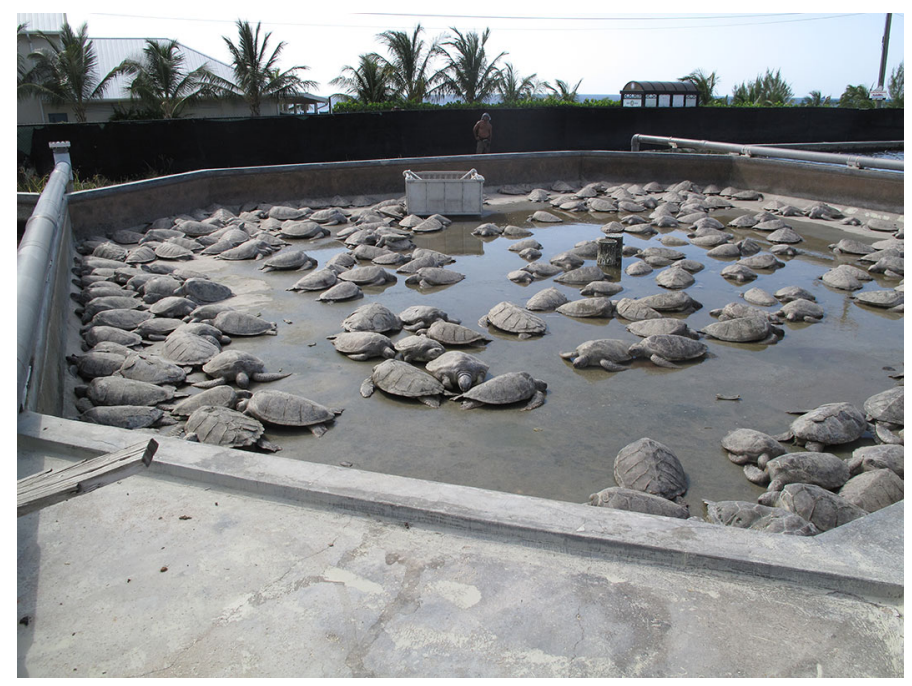

Fig. 1 A total of 299 green turtles died at the CTF after suffering from heat exhaustion when a water pipe burst. Picture obtained under FOI, 2012

Fig. 2 Image obtained using an underwater camera, 2013. Green sea turtles in a shallow barren concrete tank, with poor water quality, in the 'public facing' section of the CTF. The water quality is so poor it is difficult to see the second turtle in the background

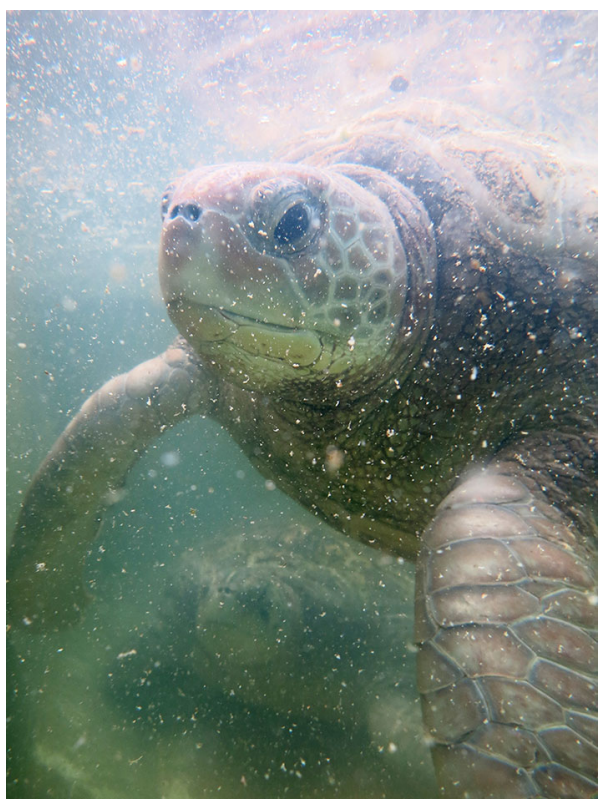

For example, from 1975 to 1983 only $3.3 \%$ or less of offspring produced by farmreared turtles survived 1 year or more (Cayman Turtle Farm 1985). Nevertheless, in 1985 , in its proposal to CITES, the CTF estimated that it could slaughter 5,000 
turtles a year (at 3-4 years of age) by hatching 10,000 eggs annually (Cayman Turtle Farm 1985).

These factors may be partly responsible for a documented fall in the number of green turtles slaughtered by the CTF. From 1,632 turtles killed in 2007 to just 762 in 2011 (Cayman Turtle Farm 2012c). Since the Department of Environment (DOE) did not report a significant increase in poaching during this period (Tim Adam pers. comms., 2013), per capita consumption of farmed turtle meat may have also fallen, perhaps due to changes in domestic consumer behaviour.

Furthermore, the failure of the CTF to obtain CITES approval to market its products internationally was, and remains, a decisive blow which prevents the CTF from recovering its high production and husbandry costs in overseas sales. This ban is unlikely to be revoked, so restrictions on CTF's marketing and sales look set to continue (WSPA 2012).

We disagree with those who opine that by providing a legal and sustainable form of meat for local consumption, the CTF is helping to conserve wild green turtle populations (Godley 2002; Cayman Turtle Farm 2012c). To our knowledge, there is no current evidence to prove that farmed sea turtle acts as an effective poaching deterrent (WSPA 2012). Perhaps other conservation efforts currently employed by the DOE, including beach protection, hunting quotas, public awareness programmes and minimisation of hatchling disorientation from lights (Bell et al. 2007), are largely responsible for the observed increase in wild green turtles nesting on local beaches and feeding in local waters. Moreover, some of these foraging turtles also may originate from other parts of the Caribbean where green turtle populations are increasing. We strongly disagree with those who argue that CTF's release of juvenile turtles (a practice known as headstarting) has also helped to increase local turtle populations, and argue instead that concerns surrounding the quarantine of these animals and levels of disease at the facility raise doubts as to the effectiveness of this conservation method. However we note that it is beyond the scope of this paper to discuss the many problems associated with this programme in detail. We believe that increased funding, man power and technical equipment to support DOE activities will be far more effective in increasing turtle populations than continued subsidies for the CTF.

In conclusion, the CTF is not unique in its inability to overcome the formidable technical and economic challenges associated with sea turtle farming, as all other formal attempts have failed (Donnelly 1994; Ross 1999). Commercialization has not contributed to unsustainable consumer demand in the Cayman Islands or high levels of poaching and associated wild turtle declines as once feared (Tim Adam, pers. comms., 2013; Cayman Turtle Farm 2012c). However, all other countries with a history of domestic green turtle consumption have chosen to reject farming as a conservation tool based on the economic and associated husbandry issues discussed above (Donnelly 1994; Ross 1999). Should the Cayman Islands Government ignore this fact, then at best, its continued farming-based approach will continue to represent a costly and largely ineffective exercise. It is unclear how long Caymanians and the wider international community will be willing to accept the economic and animal welfare costs associated with the CTF. While Government support is required to fund green turtle conservation in the Cayman Islands 
(and should be encouraged), it is clear that the CTF is not economically sustainable and appears to be an unwise investment for Caymanian green turtle conservation.

Can the Cayman Islands End Sea Turtle Farming without Decimating its Wild Population?

The CTF currently appears unwilling to terminate its sea turtle farming operation (Tim Adam, pers. comms., 2013) and cites concerns that this would lead to an unmanageable increase in poaching and decimation of wild turtle populations (Cayman Compass 2012). But without resorting to sea turtle farming, numerous countries in the Caribbean and further afield are successfully managing to maintain and restore nesting green turtle populations using conservation, regulation, and education (Jean et al. 2010). CTF should consider an excellent blueprint for the transition away from sea turtle mariculture provided by Ferme Corail on Réunion Island.

The experience of Ferme Corail provides evidence of how such a transition can be accomplished without adverse, long-term impacts on wild populations (Ciccione, pers. comms., 2012). Formerly, facility personnel collected between 5,000 and 20,000 wild green turtle hatchlings annually and raised them to marketable size (Donnelly 1994). Today Kélonia: Observatory of Marine Turtles operates as a sea turtle research, education and rescue centre (Ciccione, pers. comms., 2012). This shift was financed by the European Union and Regional Council, with research and development support from external organisations (Kélonia 2013). Conversion was expensive at just under 20 million Euros, but Kélonia is now a non-profit venture generating 'increased' revenue to cover $67 \%$ of its expenses-with an increased footfall of 100,000 tourist visits annually (Ciccione, pers. comms., 2012). Much of the remainder is provided by government and local authority subsidies for solely education and research purposes (Ciccione, pers. comms., 2012). Field work suggests that wild populations in the region have increased in recent years (Jean et al. 2010).

Change was implemented gradually and involved engagement with a range of stakeholders, providing the time required to diffuse tensions between pro and antifarming contingents (Ciccione, pers. comms., 2012). A public engagement strategy kept people informed of the rationale for change (Ciccione, pers. comms., 2012). This helped to foster a sense of shared ownership necessary to protect green turtles, and to refocus the cultural relevance of this species on to wild populations, rather than captive bred animals (Ciccione, pers. comms., 2012). We suggest that a similar gradual and integrated approach could be applied successfully in the Cayman Islands if country specific alterations were made. In fact, an unprompted transition of sorts may be underway given the CTF's recent fall in production (Cayman Turtle Farm 2012c).

A major challenge of transitioning would be the almost complete lack of data on the extent and characteristics of local demand for turtle meat in the Cayman Islands (Gina Ebanks-Petrie, pers. comms. 2013). The CTF's 'simple cash and carry' retail operation (Cayman Turtle Farm 2012d) makes it impossible to accurately determine the scale and patterns of this demand. Moreover, the CTF is currently unable to differentiate between sales to local Caymanians, its target market, and international tourists. Detailed data collation regarding the scale and characteristics of local 
demand should be made a priority. A Darwin Initiative funded study, focused on the socio-economic aspects of turtle conservation in the Cayman Islands, was initiated in 2014 which has the potential to provide a much needed initial insight. However, since data collection can be both lengthy and costly, it would be appropriate and prudent to restrict turtle meat sales to nationals to obtain preliminary data on true local demand.

\section{Conclusion}

It is clear that the activities of CTF have come at a significant cost, both in terms of captive green sea turtle welfare, mortality and the Caymanian economy (Cayman Turtle Farm 2012c). The CTF's records reveal it is not economically sound and operations continue only as a result of substantial government subsidies (Cayman Turtle Farm 2012a). Consequently, we strongly recommend that the CTF should consider terminating its commercial operation and develop a cost-effective conservation plan for a regional sea turtle rehabilitation, education and research facility.

The transition of Ferme Corail from sea turtle mariculture to research and education facility demonstrates that commercial operations can be terminated without adversely affecting wild populations (Ciccione, pers. comms., 2012). It is logical and reasonable to conclude that a similar integrated approach could succeed in the Cayman Islands if country specific alterations were made (WSPA 2012). We recommend that the CTF engage with stakeholders to develop a strategy to enable it to transition away from commercial production. Essential first steps would include prohibiting sales to visiting international tourists and assessing the true scale and patterns of local consumer demand.

Acknowledgments Many thanks to Margaret Balaskas, Thomas Morrison, Simon Pope and Elizabeth Hogan for critical comments.

Open Access This article is distributed under the terms of the Creative Commons Attribution License which permits any use, distribution, and reproduction in any medium, provided the original author(s) and the source are credited.

\section{References}

Aiken, J. J., Godley, B. J., Broderick, A. C., Austin, T. J., Ebanks-Petrie, G., \& Hays, G. C. (2001). Two hundred years after a commercial marine turtle fishery: The current status of marine turtles nesting in the Cayman Islands. Oryx, 35, 145-151.

Arena, P. C., Warwick, C., \& Steedman, C. (2014). Welfare and Environmental Implications of Farmed Sea Turtles. Journal of Agricultural and Environmental Ethics, 27, 309-333.

Balazs, G. H., Broderick, A. C., Godley, B. J. \& Work, T.M. (2013). Inspection of Cayman Turtle Farm (10-12th December, 2012): Report to the Cayman Turtle Farm (Ltd.). Unpublished report.

Bell, C. D., Parsons, J., Austin, T. J., Broderick, A. C., Ebanks-Petrie, G., \& Godley, B. J. (2005). Some of them came home: the Cayman Turtle Farm head-starting project for the green turtle y mydas. Oryx, 39, 137-148.

Bell, C. D., Solomon, J. L., Blumenthal, J. M., Austin, T. J., Ebanks-Petrie, G., Broderick, A. C., et al. (2007). Monitoring and conservation of critically reduced marine turtle nesting populations: Lessons from the Cayman Islands. Animal Conservation, 10, 39-47. 
Cayman Compass (2010). Turtle meat price tripling. Cayman Compass [Online] 8 February 2010. www. compasscayman.com/story.aspx?id=15056 [Accessed 21 Feb 2012].

Cayman Compass (2012). Turtle Farm finances questioned. Cayman Compass [Online] 16 October 2012. http://www.compasscayman.com/caycompass/2012/10/16/Turtle-Farm-finances-questioned/.

Cayman Compass (2013a). Cheaper turtle meat follows boost in production. Cayman Compass [Online] 30 August 2013. http://www.compasscayman.com/caycompass/2013/08/30/Cheaper-turtle-meatfollows-boost-in-production/.

Cayman Compass (2013b). Animal welfare concerns over increased turtle production. Cayman Compass [Online] 4 September 2013. Available at: http://www.compasscayman.com/caycompass/2013/09/ 04/Animal-welfare-concerns-over-increased-turtle-production/.

Cayman News Service (2012). Report slams Turtle Farm. Cayman News Service [Online] 13 October $2012 \mathrm{http}: / /$ caymannewsservice.com/science-and-nature/2012/10/13/report-slams-turtle-farm.

Cayman Turtle Farm (1985). Proposal to transfer from Appendix I to Appendix II the captive population of Chelonia mydas in the Cayman Islands. Submitted by CITES Management Authority of the United Kingdom of Great Britain and Northern Ireland pursuant to Conference Resolution 3.15 on Ranching.

Cayman Turtle Farm. (2002). Application to register a captive breeding operation involving Chelonia mydas on Grand Cayman, Cayman Islands. Submitted by the CITES Management Authority of the United Kingdom of Great Britain and Northern Ireland pursuant to Conference Resolution, 11, 14.

Cayman Turtle Farm (2012a). Data obtained via a freedom of information request (FOI) received on 14.12. 12).

Cayman Turtle Farm (2012b). Data obtained via a freedom of information request (FOI) received on 19.12. 12).

Cayman Turtle Farm (2012c). Data obtained via a freedom of information request (FOI) received on 20.08.12).

Cayman Turtle Farm (2012d). Data obtained via a freedom of information request (FOI) received on 28.12. 12).

Cayman Turtle Farm (2013a). Data obtained via a freedom of information request (FOI) received on 21.01.13).

Cayman Turtle Farm (2013b). Data obtained via a freedom of information request (FOI) received on 31.05.13).

Cayman Turtle Farm (CTF) (2013c). About Us, Cayman Turtle Farm Island Wildlife Encounter [Online]. www.turtle.ky/about-us [Accessed 19 March 2013].

Dodd, K. (1982). Does sea turtle aquaculture benefit conservation? In K. A. Bjorndal (Ed.), Biology and Conservation of Sea Turtles (p. 473-480). Smithsonian Institution. Press: Washington D.C.

Donnelly, M. (1994). Sea Turtle Mariculture: A Review of Relevant Information for Conservation and Commerce. Washington, DC, USA: The Centre for Marine Conservation.

Donnelly, M. (2011). Sea Turtles and CITES. SWOT Report, Vol VI. In R. B. Mast, B. J. Hutchinson, B. Wallace, L. Yarnell \& S. Hoyt (Eds.) (pp. 42-43). Arlington: State of the World's Sea Turtles.

Duguay, D. (2009). Special Report of the Auditor General on the Loans and Expenditures of Funds at Boatswain's Beach. Office of the Auditor General Cayman Islands. Published October 2009. www.gov. ky/pls/portal/docs/PAGE/CIGHOME/FIND/ORGANISATIONS/AZAGENCIES/AUD/SPECIAL REPORTS/BOATSWAINSBEACHLOANSEXPENDITURESFINALOCTOBER212009.PDF [Accessed $21 \mathrm{Feb} 2012]$.

Dutton, A. J., Hepburn, C., \& MacDonald, D. (2011). A Stated Preference Investigation into the Chinese Demand for Farmed vs. Wild Bear Bile. PLoS One, 6(7), e21243.

Ehrenfeld, D. 1982. Options and limitations in the conservation of sea turtles. In K. A. Bjorndal (Ed.), Conservation of Sea Turtles (pp.457-463). Biology. Smithsonian Institution. Press: Washington D.C.

Fosdick, P., \& Fosdick, S. (1994). Last Chance Lost?. York, PA: Irvin S. Naylor.

Frazier, J. (2003) Prehistoric and ancient historic interactions between humans and marine turtles. In P. L. Lutz, J. A. Musick \& J. Wyneken (Eds.), Biology of Sea Turtles Vol II (pp. 1-38). Boca Raton: CRC Press.

Godley, B. J. (2002) Cayman Turtle farm: Consultancy report to DEFRA 15 September 2002, pp.23.

Jean, C., Ciccione, S., Ballorain, K., Georges, J., \& Bourjea, J. (2010). Ultralight aircraft surveys reveal marine turtle population increases along the west coast of Reunion Island. Oryx, 44, 223-229.

Kélonia (2013). About Kélonia. http://www.kelonia.org/fr/00-GB/Kelonia/About-Kelonia.html [Accessed 05 August 2013]. 
Lutcavage, M. E., Plotkin, P., Witherington, B., \& Lutz, P. L. (1997). Human impacts on sea turtle survival. In P. L. Lutz \& J. A. Musick (Eds.), The Biology of Sea Turtles. New York: CRC Press.

Morriss, A. (2006). Survival of the Sea Turtle-Cayman Turtle Farm Starts Over. The Property and Environment Research Center (PERC). [Online] PERC Reports: Vol 24, No.3. Available.

Pritchard, P. C. H. (2011). The most valuable reptile in the world the green turtle. In R. B. Mast, B. J. Hutchinson, B. Wallace, L. Yarnell \& S. Hoyt (Eds.) (pp. 24-29), SWOT Report, Vol VI. Arlington: State of the World's Sea Turtles.

Ross, J. P. (1999). Ranching and Captive Breeding Sea Turtles: evaluation as a conservation strategy. In K. L. Eckert, K. A. Bjorndal, F. A. Abreu-Grobois \& M. Donnelly (Eds.), Research and Management Techniques for the Conservation of Sea Turtles, IUCN/SSC Marine Turtle Specialist Group, Publication No. 4 (pp. 197-201). Washington.

Warwick, C., Arena, P. C., \& Steedman, C. (2012). Health implications associated with exposure to farmed and wild sea turtles. Journal of the Royal Society of Medicine, 4(1), 8.

Wildlife Extra (2012) 300 Turtles Die at Cayman Turtle Farm. http://www.wildlifeextra.com/go/news/ cayman-turtle-farm.html\#cr [accessed 10 August 2012].

Wood, J. R., \& Wood, F. E. (1990). Successful production of captive F2 generation of the green sea turtle. Marine Turtle Newsletter, 50, 3-4.

WSPA. (2012). The Cayman Turtle Farm, a case for change. London, UK: The World Society for the Protection of Animals. 